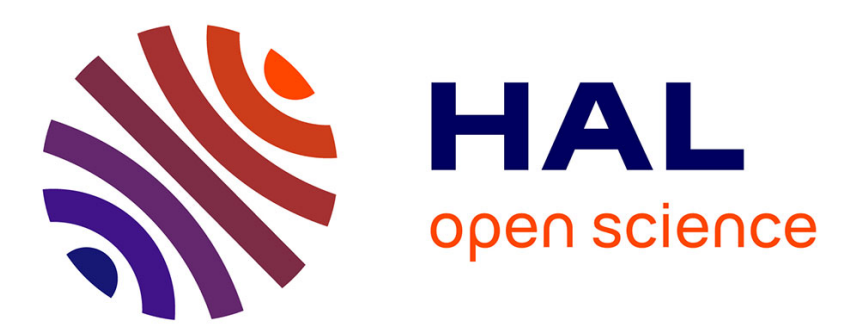

\title{
Fast and efficient approach to predict EMC immunity of complex equipment after a component change
}

Saliha Chetouani, Sébastien Serpaud, Alexandre Boyer, Sonia Ben Dhia

\section{To cite this version:}

Saliha Chetouani, Sébastien Serpaud, Alexandre Boyer, Sonia Ben Dhia. Fast and efficient approach to predict EMC immunity of complex equipment after a component change. EMC Europe 2020, Sep 2020, Rome (online), Italy. hal-02951845

\section{HAL Id: hal-02951845 \\ https://hal.laas.fr/hal-02951845}

Submitted on 29 Sep 2020

HAL is a multi-disciplinary open access archive for the deposit and dissemination of scientific research documents, whether they are published or not. The documents may come from teaching and research institutions in France or abroad, or from public or private research centers.
L'archive ouverte pluridisciplinaire HAL, est destinée au dépôt et à la diffusion de documents scientifiques de niveau recherche, publiés ou non, émanant des établissements d'enseignement et de recherche français ou étrangers, des laboratoires publics ou privés. 


\section{Fast and efficient approach to predict EMC immunity of complex equipment after a component change}

\author{
Saliha Chetouani, Sébastien Serpaud \\ IRT Saint-Exupéry, \\ LAAS-CNRS, Toulouse, France \\ saliha.chetouani@irt-saintexupery.com
}

\author{
Alexandre Boyer, Sonia Ben Dhia \\ Univ. de Toulouse, INSA, \\ LAAS-CNRS, Toulouse, France \\ alexandre.boyer@insa-toulouse.fr
}

\begin{abstract}
This paper describes a fast methodology for managing the obsolescence issues of components in industrial equipment (aeronautical and/or automotive). The objective is to predict Electromagnetic Compatibility (EMC) non-compliance risk or guarantee a non-regression of EMC performances, in conducted immunity, after a component change. This could be achieved through an equivalent test at the component level if the residual voltage at its pins could be estimated. Accordingly, this approach aims to decline conducted immunity requirements, from the connector at the input of an equipment to an obsolete component placed on one of its boards. Which must constitute a faster and cheaper solution than systematic EMC qualification test of the equipment each time a component is replaced.
\end{abstract}

Keywords-Obsolescence, Conducted immunity, Multiport, $S$ Parameters, Indirect measurement, De-embedding.

\section{INTRODUCTION}

A simple comparison of the commercial lifetime of electronic components (approximately 3 to 5 years) and that of electronic equipment and systems (15 to 40 years for an aircraft, for example) shows the inevitable problem of rapid obsolescence of components. To remain compliant with standards, any change of an obsolete component must lead the Original Equipment Manufacturers (OEM) to requalify their products to prove the non-regression of their EMC performances. The requalification usually requires timeconsuming tests, significant costs and delays. Currently, the standard EMC measurement method is the only authorized method to validate EMC of an equipment. This paper propose an approach based on the EMC measurement at component level to estimate the non-regression of equipment in the context of the component obsolescence.

In context of the immunity test, the proposed approach propose to decline the disturbance in the boundary of component. Since, the EMC risk assessment could be done by a conducted immunity test done on the component to replace. The type of disturbances and the applied levels should be representative of the component environment at the equipment level and how it is mounted. The Direct Power Injection (DPI) method or the Near-Field Scanning in Immunity (NFSi) measurement method could be used to test this constraint at the component level.

This paper presents a methodology to evaluate the risk level of immunity regression due to a change of a component in a complex electronic equipment. Fig. 1. presents an example of typical aeronautic equipment considered in this study: e.g. four (or more) daughter boards mounted on one or two backplane boards, inside a metal enclosure and interconnected to harness through a wide connector. Different approaches have been deployed for managing electronic component obsolescence. A common approach proposes a complete and exact modeling of the equipment according to a bottom-up vision. It consists in the development of models at the component level, then at the electronic board level and finally at the equipment level, which are interconnected together [1] [2] [3] [4]. They are usually based on electromagnetic modeling 3D and Full-Wave simulations [5]. However, these approaches quickly find their limits because of the diversification, the complexity of the equipment and their EMC requirements. The long calculations time required to build models is also a main limitation. In addition, the exact information regarding each part of the equipment is not necessarily known because of confidentiality reasons. These drawbacks severely limit the use of these methods and could be, in some cases, not envisaged due to the cost and delays.

In this paper, an experimental approach to deal with this issue is presented. It consists in declining the external perturbations from the equipment level (a common mode disturbance injected into one or more equipment inputs) which arrive to the obsolete component (placed on a daughterboard). Then the residual level of disturbance applied to the component can be estimated, which will serve as a reference level for an immunity test on the new component. The purpose of this study is to predict, from some partial measurements at the input of the equipment, the level of risk due to a component change.

If non-linear effect could be neglected, an S-parameter based black box can efficiently model the filtering effect of the equipment. It build from measurements done between the input connector of the equipment and the pad of the component to be replaced. However, putting in practice such a measurement is not straightforward as the measurement ports at component side are not accessible easily. The originality of the proposed approach is to use an indirect Sparameter measurement method based on [6] to build the black box model of equipment.

From this equipment model, it is possible to decline the normative constraint declined at the input of equipment to the input of component such as the common or differential voltage applied to the pins of the component to change.

Note the modeling of the test setup is not covered by the study. Here we assume a declined constraint at the input of equipment (connector) as a common mode generator.

After a general description of the proposed approach, an experimental case study dedicated to the validation of the method is presented.

\section{GENERAL ASSUMPTIONS OF THE PROPOSED APPROACH}

As described in the introduction, this study concerns the obsolescence of components of industrial equipment (e.g. aeronautical, automotive). However, to simplify the study, the following assumptions and choices are made: 

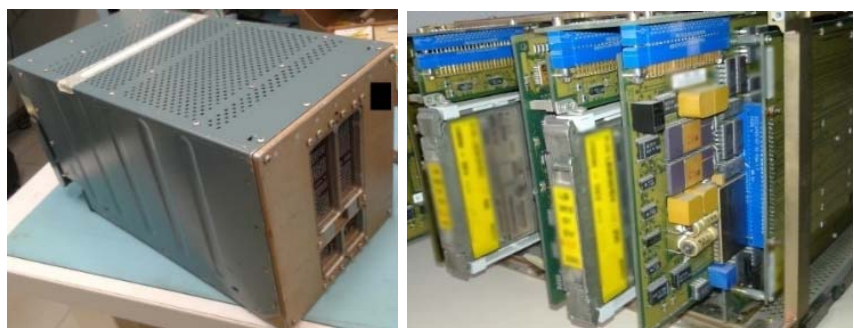

Normative

constraints

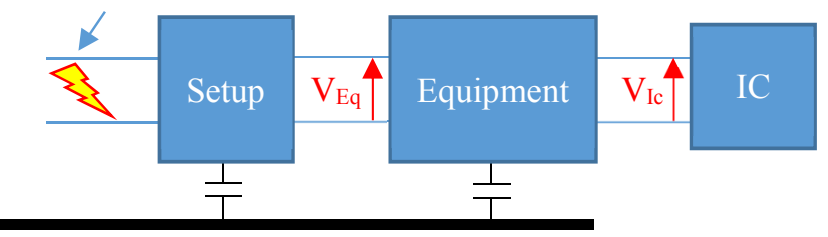

Fig. 1. Propagation of a conducted disturbance to an obsolete component; Example of an aeronautical equipment and its boards (top)

- The studied systems are assumed reciprocal and linear. The non-linear behavior of the components (e.g. active circuits, protection structures, etc.) is neglected.

- The general ground of the system, which is usual in electronic equipment mounted in shielded enclosure, could be different from the local component ground (usually a local ground plane at PCB level).

- The conducted injection on the harness is of the common mode type.

- The disturbance induced by the injection system and driving on the harness is modeled as an equivalent source placed at the input connector of the equipment.

- The component terminals are not accessible to place an S-parameter measurement port, but the component can be removed and replaced by some passive loads.

The purpose of the proposed approach is to determine the influence of the equipment on the propagation of a conducted disturbance to an obsolete component, only from measurements made on the input of the equipment. It aims to estimate either the single-ended or the differential voltages applied to the different pins of the component to be replaced.

\section{DESCRIPTION OF THE INDIRECT MEASUREMENT METHOD}

S-parameters are a powerful formalism to characterize the electromagnetic behavior of passive electronic devices, especially in the case of very complex equipment and components. The state of art on S-parameters estimation of a 2-port device without directly measuring the two ports is quite rich. Reference [7] presents a synthesis on some methods and proposes a simple and an interesting technique. It consists in determining the four S-parameters from three measurements done at the only accessible port, by connecting three loads on the second inaccessible port. The previous method can be extended to the case of an N-port device, formed by any number of ports. We provide in the following part a generalized technique, which was developed by [6]. It is based on the same principle and allows estimating analytically the S-parameters of multiport device with hard-to-access ports, which models the filtering effect applied by the equipment on the conducted disturbance from the input connector to the obsolete component.

\section{A. General description of the method}

We consider a system with $\mathrm{N}$ ports $(\mathrm{N}=2 \mathrm{r})$, as illustrated in Fig. 2. The $r$ ports on the left, denoted by the index a, are considered as the direct-measured ports (in the case of an equipment, the pins of the input connector). The other $r$ ports on the right represent the indirect-measured ports, inaccessible by the measurement probe, denoted by the index $\mathbf{u}$.

The matrix [S $\mathbf{S}_{\text {tot] }}$ of the multiport system could be written in terms of three submatrices $\mathbf{S}_{\mathbf{a a}}, \mathbf{S}_{\mathbf{a u}}$ and $\mathbf{S}_{\mathbf{u u}}$, defined in (1). As the system is supposed, the submatrix $S_{u a}$ is equal to the transpose of $\mathbf{S a u}\left(\mathbf{S}_{\mathbf{a u}}^{\mathrm{T}}\right)$. The matrix $\mathbf{a}=\left[\mathrm{a}_{\mathrm{a}}^{\mathrm{T}} \mathrm{a}_{\mathrm{u}}^{\mathrm{T}}\right]^{\mathrm{T}}$ contains the incident power waves and $\mathbf{b}=\left[\mathrm{b}_{\mathrm{a}}^{\mathrm{T}} \mathrm{b}_{\mathrm{u}}^{\mathrm{T}}\right]^{\mathrm{T}}$ the reflected power waves.

$$
\left[\begin{array}{l}
b_{a} \\
b_{u}
\end{array}\right]=\left[\begin{array}{ll}
S_{a a} & S_{a u} \\
S_{u a} & S_{u u}
\end{array}\right]\left[\begin{array}{l}
a_{a} \\
a_{u}
\end{array}\right]
$$

where $\mathrm{S}_{\mathrm{aa}}, \mathrm{S}_{\mathrm{au}}, \mathrm{S}_{\mathrm{uu}} \in \mathrm{C}^{r \times r}$ and $\mathrm{a}_{\mathrm{a}}, \mathrm{b}_{\mathrm{a}}, \mathrm{a}_{\mathrm{u}}, \mathrm{b}_{\mathrm{u}} \in \mathrm{C}^{r \times 1}$.

In order to estimate all the S-parameters, we connect a set of known loads (1-port) to the $\mathrm{u}$ ports. Their reflection coefficients constitute the diagonal of the load matrix noted $\left[\mathbf{S}_{\mathbf{L}}\right]$. The matrix $\widehat{\boldsymbol{S}}$ designates the measured S-parameters from the direct-measured ports. The equivalent source at the input of the multiport inject the incident waves $\mathbf{a}_{\mathbf{a}}$, it follows that:

$$
b_{a}=\hat{S} a_{a}
$$

Contrary to the waves $\mathbf{a}_{\mathbf{a}}$, the incident waves $\mathbf{a}_{\mathbf{u}}$ result from the reflection of $\mathbf{b}_{\mathbf{u}}$ on the loads, therefore:

$$
a_{u}=S_{L} b_{u}
$$

Substituting the terms in (2) and (3) to (1) yields to (4).

$$
\widehat{S}=S_{a a}+S_{a u} S_{L}\left(I-S_{u u} S_{L}\right)^{-1} S_{a u}{ }^{T}
$$

where $\mathbf{I}$ is the identity matrix.

Equation (4) is the main formula connecting the matrix of the measured S-parameters to the three corresponding submatrices of the multiport. The method to extract the three submatrices are described in the following parts.

\section{B. Estimation of Saa}

There are two ways to estimate the Saa matrix. If perfectly matched loads can be placed at inaccessible ports $\left(\mathrm{S}_{\mathrm{L}}=0\right)$, Saa is directly equal to the matrix of the measured S-parameters using this load-set according to (4).

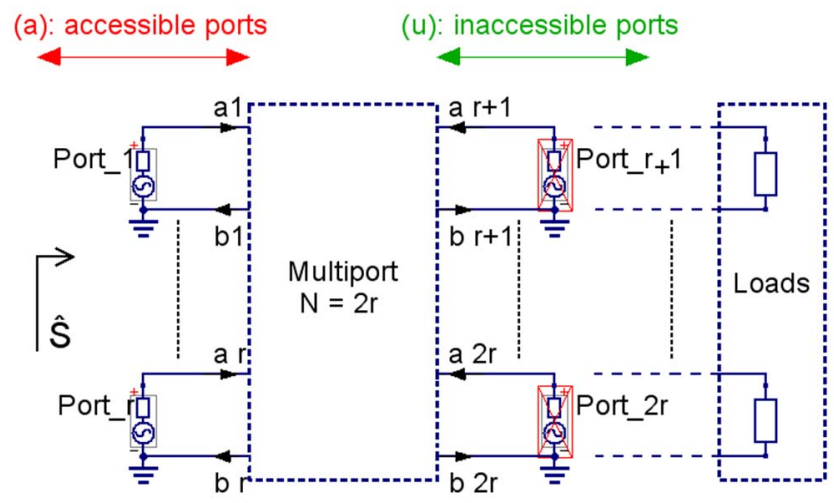

Fig. 2. Schematic illustration of the studied system with $\mathrm{N}=2 \mathrm{r}$ ports 
If it is complicated to obtain suitable matched loads (especially for very high frequencies), Saa can be estimated using three load-sets of arbitrary value as follow: we conduct two measurements $(\mathbf{i}, \mathbf{j})$ with two different known-load sets. We note by $\mathbf{S}_{\mathbf{L}}{ }^{(\mathbf{i})}$ and $\mathbf{S}_{\mathbf{L}}{ }^{(\mathbf{j})}$ the reflection coefficients of loads used in the measurements $\widehat{\mathbf{S}}^{(i)}$ and $\widehat{\mathbf{S}}^{(\mathbf{j})}$ respectively.

By reversing the both sides of (4) and taking the differences of equations for the two measurements, (5) can be derived.

$$
\begin{gathered}
S_{a u}{ }^{T}\left(\hat{S}^{(i)}-S_{a a}\right)^{-1} S_{a u}-S_{a u}{ }^{T}\left(\hat{S}^{(j)}-S_{a a}\right)^{-1} S_{a u} \\
=S_{L}{ }^{(i)-1}-S_{L}{ }^{(j)-1}
\end{gathered}
$$

Expanding (5) and reversing both sides of the equation leads to (6).

$$
\begin{gathered}
\left(\hat{S}^{(j)}-\mathrm{S}_{\mathrm{aa}}\right)\left(\hat{S}^{(j)}-\hat{S}^{(i)}\right)^{-1}\left(\hat{S}^{(i)}-\mathrm{S}_{\mathrm{aa}}\right) \\
=S_{a u}\left(S_{L}{ }^{(i)-1}-S_{L}^{(j)-1}\right)^{-1} S_{a u}{ }^{T}
\end{gathered}
$$

A third measurement $\widehat{\mathbf{S}}^{(\boldsymbol{k})}$ is performed. By replacing $\mathrm{j}$ in (6) by $\mathrm{k},(7)$ can be written.

$$
\begin{gathered}
\left(\hat{S}^{(k)}-S_{a a}\right)\left(\hat{S}^{(k)}-\hat{S}^{(i)}\right)^{-1}\left(\hat{S}^{(i)}-S_{a a}\right) \\
=S_{a u}\left(S_{L}{ }^{(i)-1}-S_{L}{ }^{(k)-1}\right)^{-1} S_{a u}{ }^{T}
\end{gathered}
$$

If the three loads are selected such as, their reflections coefficients are related to a non-zero constant $\mathrm{k} 1$ defined by (8), (6) and (7) can be combined to extract the submatrix Saa according to (9).

$$
\begin{gathered}
\boldsymbol{k}_{\mathbf{1}}=\left(S_{L}{ }^{(k)-1}-S_{L}{ }^{(i)-1}\right)\left(S_{L}{ }^{(j)-1}-S_{L}{ }^{(i)-1}\right)^{-1} \\
\boldsymbol{S}_{\boldsymbol{a} \boldsymbol{a}}=\left(\widehat{\boldsymbol{S}}^{(j)} \boldsymbol{k}_{\mathbf{2}}-\boldsymbol{k}_{\mathbf{1}} \widehat{\boldsymbol{S}}^{(\boldsymbol{k})} \boldsymbol{k}_{\mathbf{3}}\right)\left(\boldsymbol{k}_{\mathbf{2}}-\boldsymbol{k}_{\mathbf{1}} \boldsymbol{k}_{\mathbf{3}}\right)^{-1}
\end{gathered}
$$

where:

$$
\begin{aligned}
& \boldsymbol{k}_{\mathbf{2}}=\left(\hat{S}^{(j)}-\hat{S}^{(i)}\right)^{-1} \text { and } \quad \boldsymbol{k}_{\mathbf{3}}=\left(\hat{S}^{(k)}-\hat{S}^{(i)}\right)^{-1} \\
& \text { C. Estimation of } \text { Sau }
\end{aligned}
$$

Estimating the Sau matrix is the most complex part. The authors of this technique have proposed different methods [8] [9] [10]. We present in this part, the easiest one to use and we mention the references of the others, which are more mathematically complicated.

Replacing Saa expression in (6) with its formula defined by (9) leads to a quadratic equation in terms of Sau. We defined, in the previous part, the loads matrix in terms of the reflection coefficients, such as:

- $\quad \mathbf{S}_{\mathbf{L}}{ }^{(\mathbf{i})}=\operatorname{diag}\left[\mathrm{sl}^{(\mathrm{i})}, \ldots \ldots ., \mathrm{sl}^{(\mathrm{i})}\right]$, for the $1^{\mathrm{st}}$ measurement;

- $\quad \mathbf{S}_{\mathbf{L}}{ }^{(\mathrm{j})}=\operatorname{diag}\left[\mathrm{sl}^{(\mathrm{j})}, \ldots \ldots, \mathrm{sl}^{(\mathrm{j})}\right]$, for the $2^{\text {nd }}$ measurement;

- $\quad \mathbf{S}_{\mathbf{L}}{ }^{(\mathbf{k})}=\operatorname{diag}\left[\mathrm{sl}^{(\mathrm{k})}, \ldots ., \mathrm{sl} \mathbf{l}^{(\mathrm{k})}\right]$, for the $3^{\text {rd }}$ measurement;

To estimate Sau we conduct additional measurements noted by $\widehat{\mathbf{S}}^{(f)}$, using a set of loads consisting of the first and the second loads as follows:

- $\quad \mathbf{S}_{\mathbf{L}}{ }^{(\mathbf{f})}=\operatorname{diag}\left[\mathrm{sl}^{(\mathbf{j})}, \mathrm{sl}^{(\mathbf{i})}, \ldots, \mathrm{sl}^{(\mathbf{i})}\right]$, for the $4^{\mathrm{rd}}$ measurement;

The indirect-measured ports, from $r+2$ to $2 r$, must be terminated by the load used in the first measurement. Only the port $\mathrm{r}+1$ must be terminated by the load used in the second measurement.
Replacing the terms $\mathrm{S}_{\mathrm{L}}{ }^{(\mathrm{k})}$ in $(7)$ by $\mathrm{S}_{\mathrm{L}}{ }^{(\mathrm{f})}$ gives:

$$
\begin{gathered}
\left(\hat{S}^{(i)}-S_{a a}\right)^{-1}\left(\hat{S}^{(f)}-\hat{S}^{(i)}\right)\left(\hat{S}^{(f)}-S_{a a}\right)^{-1} \\
=S_{a u}{ }^{T-1}\left(S_{L}{ }^{(i)-1}-S_{L}{ }^{(f)-1}\right) S_{a u}{ }^{-1}
\end{gathered}
$$

Denoting the left hand side of (10) as $\mathbf{M}$ and the elements of the matrix $\mathrm{S}_{\mathrm{au}}{ }^{-1}$ as $S t_{x y}$, the above equation becomes:

$$
\begin{aligned}
& \mathbf{M}=\left(\frac{1}{\mathrm{Sl}^{(\mathrm{i})}}-\frac{1}{\mathrm{Sl}^{(\mathrm{j})}}\right)
\end{aligned}
$$

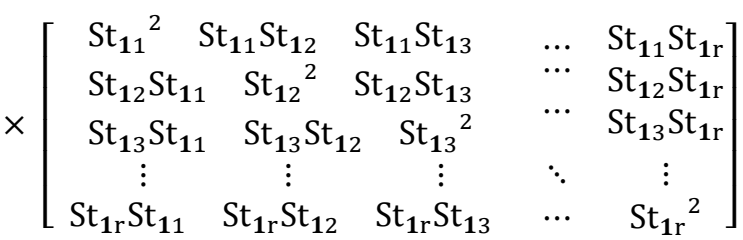

Equation (11) allows calculating the square of the different terms of the $1^{\text {st }}$ row of the matrix $\mathrm{S}_{\mathrm{au}}{ }^{-1}$. By repeating the operation for each of the other ports $(\mathrm{r}+2, \ldots ., 2 \mathrm{r})$, we obtain all the coefficients of $\mathrm{S}_{\mathrm{au}}{ }^{-1}$ and then the matrix $\mathrm{S}_{\mathrm{au}}$ as the inverse of the matrix $\mathrm{S}_{\mathrm{au}}{ }^{-1}$.

It should be noted that the square root operation implies two solutions of $\mathrm{S}_{\mathrm{au}}\left(+\mathrm{S}_{\mathrm{au}}\right.$ and $\left.-\mathrm{S}_{\mathrm{au}}\right)$. The choice of the sign does not affect the magnitude of the calculated parameters (Sau, Suu) and the estimated single-ended voltages. However, it involves a phase inversion. In addition, it influences the magnitude and the phase of the differential voltage. The ambiguity of the sign could be resolved by a solution proposed in [10]. Which is not envisaged in our study, since it requires adding an extra known connection between the direct and the indirect ports. We have developed a new correction algorithm, explained in the next part, to solve this inverse problem of the sign of Sau matrix.

\section{Sign ambiguity correction algorithm}

In order to choose the right solution between the two mathematical solutions given by the previous calculation, we propose an analysis based on the physical characteristics of the studied systems. We supposed that the systems are mainly composed of transmission lines with some EMC filters. The transmission S-parameters between input and output ports have a negative phase. This is explained by the causal nature of the systems. For example, for a two-port network, the transmission matrix (chain matrix) can be expressed according to the characteristics of the transmission line (the characteristic impedance $\mathbf{Z c}$, the propagation constant $\mathbf{G}$, the length $\mathbf{L}$, the propagation speed $\mathbf{v}$ and the angular frequency $\boldsymbol{\omega}$ ) as follows:

$$
\left[\begin{array}{ll}
A & B \\
C & D
\end{array}\right]=\left[\begin{array}{cc}
\operatorname{ch}(G . L) & Z c . s h(G . L) \\
\operatorname{sh}(G . L) / Z c & \operatorname{ch}(G . L)
\end{array}\right]
$$

The transmission parameter $S_{12}$ can be expressed using the conversion relations between the $\mathrm{ABCD}$ matrix and the $\mathrm{S}$ matrix [11].

$$
S_{12}=1 / \exp (G . L)=\exp (-G . L)
$$

where $G=\alpha+j \cdot \beta$ ( $\alpha$ is the attenuation constant $\geq 0$ and $\beta=\omega / \nu$ is the phase constant $\geq 0$ ). Therefore:

$$
\text { phase }\left(S_{12}\right)=-\beta . L=-\omega \mathrm{L} / \nu
$$


Hence, the phase of the transmission parameter $\mathrm{S}_{12}$ is negative whatever the frequency. This demonstration could be generalized to an N-port network.

The correction algorithm contains therefore two stages:

- $\quad$ First, in low frequencies, we calculate the phases of the two Sau values and we choose the value whose phase is negative. The signs of the other parameters (extra diagonal parameters) are determined from the signs of these transmission parameters (diagonal parameters).

- Then, we start with a frequency point, corrected in the first step, and we calculate the difference (in absolute value) between the phases of two successive points. The value of this difference must be between two thresholds (low threshold $60^{\circ}$ and high threshold $340^{\circ}$ ). Otherwise, we should reverse the sign of the second point.

\section{E. Estimation of Suu}

The submatrix Suu can be calculated directly be replacing Saa and Sau obtained previously in (15). A reflection coefficient $\left(\mathrm{S}_{\mathrm{L}}{ }^{(\mathrm{i})}\right.$, for example) can be used with its corresponding measurement $\left(\widehat{\mathrm{S}}^{(i)}\right)$.

$$
S_{u u}=S_{L}^{-1}-S_{a u}{ }^{T}\left(\widehat{S}-S_{a a}\right)^{-1} S_{a u}
$$

\section{F. Estimation of S-parameters of the component to replace}

Finally, the estimation of these three sub-matrices allows creating the matrix [Stot], which represents the influence of the equipment on the propagation of the conducted disturbance to an obsolete component. Once determined, the S-parameters of the component, noted as $\mathbf{S}_{\mathbf{I C}}$, can be easily estimated. In (15) $\mathrm{S}_{\mathrm{L}}$ is replaced by $\mathrm{S}_{\mathrm{IC}}$, therefore leading to (16)

$$
S_{I C}=\left(S_{u u}+S_{a u}{ }^{T}\left(\widehat{S_{I C}}-S_{a a}\right)^{-1} S_{a u}\right)^{-1}
$$

One measurement is conducted with connecting the obsolete component to obtain $\widehat{S_{I C}}$, the measurement Sparameters when it is connected. The calculated matrix is a diagonal matrix corresponding to the S-parameters associated with each port of the component. The matrix multiplication in (16) removes the sign ambiguities of $\boldsymbol{S}_{\boldsymbol{a u}}$

\section{ESTIMATION OF THE APPLIED VOLTAGE ON THE TERMINALS OF THE FUTURE COMPONENT}

This section explains how to calculate the residual voltage at the components pins from the S-parameter matrix [S $\left.\mathbf{S}_{\text {tot }}\right]$ estimated previously. A differential voltage, expressed as the difference of the residual voltages applied on two pins, must be computed.

Let $\mathbf{j}$ be a port of a multiport system, as presented in Fig. 2. The port voltage $\mathbf{V} \mathbf{j}$ is the sum of the incident and the reflected voltage noted by $\mathbf{V} \mathbf{j i}$ and $\mathbf{V j}$ r respectively.

The incident and reflected power ( $a j$ and $b_{j}$ ) related to the port $\mathrm{j}$ can be expressed by the incident and the reflected voltage as well:

$$
a_{j}=V_{j i} / \sqrt{ } Z_{0} \text { and } \quad b_{j}=V_{j r} / \sqrt{ } Z_{0}
$$

where $\mathbf{Z}_{0}$ is the port impedance.
The single-ended port voltage $\mathrm{Vj}$ can be expressed according to $(18)$.

$$
V_{j}=V_{j i}+V_{j r}=\sqrt{Z_{0}}\left(a_{j}+b_{j}\right)
$$

Without any loss of generality, a 4-port device is considered, with two direct ports and two indirect ports. Let $\mathbf{V} \mathbf{p}$ be the internal voltage source of a simultaneous injection of a common source noise on the direct ports, and $\mathbf{S p}$ the internal reflection coefficient as shown in Fig. 3. The incident and reflected powers applied on the different ports are related by (19) [8].

$$
\left[\begin{array}{l}
a_{1} \\
a_{2} \\
a_{3} \\
a_{4}
\end{array}\right]=\left[\begin{array}{llll}
S_{p} & 0 & 0 & 0 \\
0 & S_{p} & 0 & 0 \\
0 & 0 & S_{l_{-} 3} & 0 \\
0 & 0 & 0 & S_{l_{-} 4}
\end{array}\right]\left[\begin{array}{l}
b_{1} \\
b_{2} \\
b_{3} \\
b_{4}
\end{array}\right]+\frac{V_{p}}{2 \sqrt{z_{0}}}\left[\begin{array}{l}
1 \\
1 \\
0 \\
0
\end{array}\right]
$$

which can be rewritten in a more compact way:

$$
a=S_{A} b+p
$$

Thus, the quantities $\mathrm{a}$ and $\mathrm{b}$ can be expressed in terms of the estimated S-matrix [Stot] as follows [8]:

$$
\begin{gathered}
a=\left(I-S_{A} S_{t o t}\right)^{-1} \\
b=S_{t o t}\left(I-S_{A} S_{t o t}\right)^{-1} p
\end{gathered}
$$

By combining (20) and (21) with (18), the residual differential voltage between the indirect ports can be calculated according to (22).

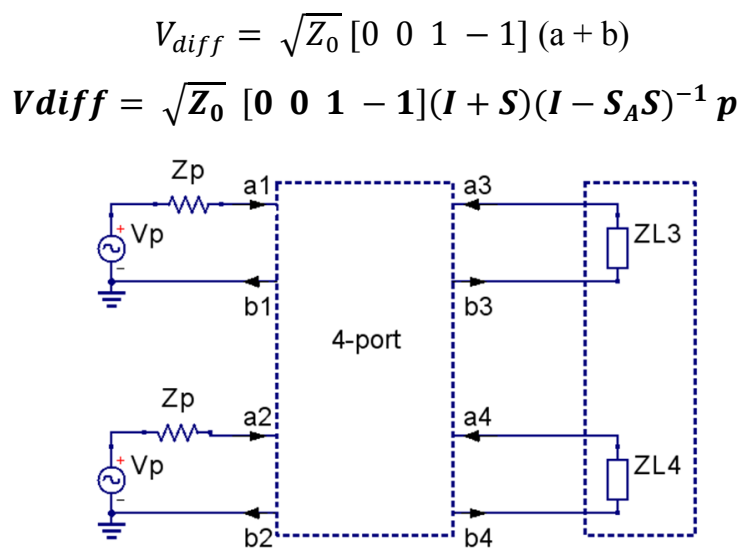

Fig. 3. Example of a common source disturbance injected on the direct ports

\section{CASE STUDY}

The proposed case study, shown in Fig. 4, is a 4-port board containing two coupled microstrip lines routed on a FR4 substrate 4-layers PCB. This case study represents a simple equipment to illustrate easily the proposed approach. The studied component is represented by two passive loads ( 560 $\Omega$ and $100 \Omega$ ) soldered on SMA connectors and placed on ports 3 and 4 respectively (Fig. 5).

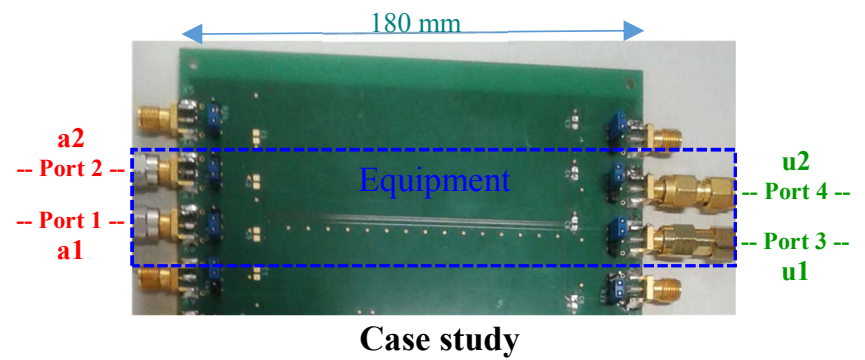

Fig. 4. Case study description (PCB board) 


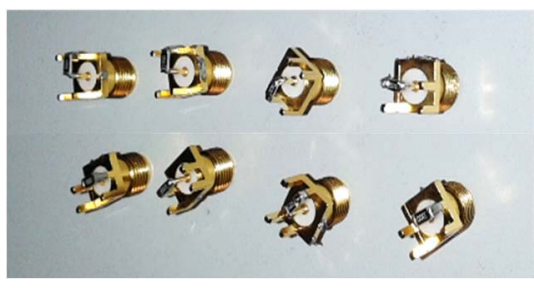

SMA Load-sets/IC

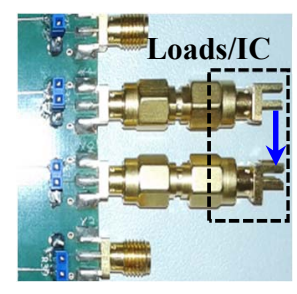

Residual voltage

Fig. 5. Case study description (Loads)

The objective is to estimate, only from the S-parameter measured at the direct ports (port 1 [a1] and port 2 [a2]) the residual voltage at the component pins (port $3[\mathrm{u} 1]$ and port 4 [u2]). The S-parameter matrix of the equipment can be developed as shown in Fig. 6. The three submatrices can be estimated from III. The results will be compared to a direct 4port measurement at the Vector Network Analyzer (VNA) from $100 \mathrm{kHz}$ to $3.5 \mathrm{GHz}$.

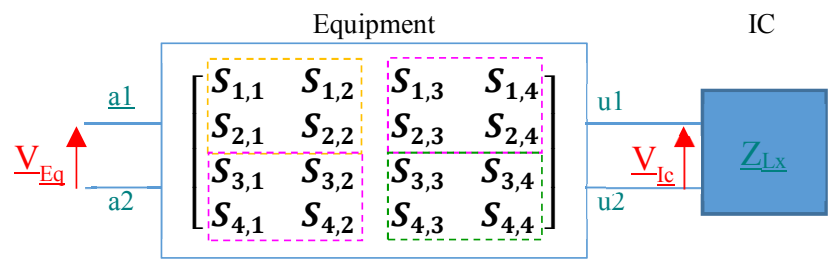

Saa-matrix

Sau-Matrix

Suu-Matrix

Fig. 6. Estimated S-parameter matrix of the equipment

As described in section (III), several measurement configurations are necessary to extract all submatrices. The following table summarizes all these configurations. No other measurements are required to calculate the matrix Suu. It is calculated from the previous measurements.

TABLE I. SUMMARY OF THE MEASURMENT CONFIGURATION TO EXTRACT THE SUBMATRICES SAA, SAU AND MEASURMENT WITH THE STUDIED COMPONENT

\begin{tabular}{|c|c|c|c|c|c|c|}
\hline Matrix & \multicolumn{3}{|c|}{ Saa } & \multicolumn{2}{c|}{ Sau } & \\
\hline $\begin{array}{c}\text { Load- } \\
\text { sets used }\end{array}$ & ZL1 & ZL2 & ZL3 & $\begin{array}{c}\{\text { ZL2, } \\
\text { ZL1 }\}\end{array}$ & $\begin{array}{c}\{\text { ZL2, } \\
\text { ZL1 }\}\end{array}$ & Component \\
\hline Port 3 & $820 \Omega$ & $100 \Omega$ & $560 \Omega$ & $100 \Omega$ & $820 \Omega$ & $560 \Omega$ \\
\hline Port 4 & $820 \Omega$ & $100 \Omega$ & $560 \Omega$ & $820 \Omega$ & $100 \Omega$ & $100 \Omega$ \\
\hline
\end{tabular}

We present in Fig. 7. and Fig. 8. an example of some parameters measured directly and those estimated indirectly (using the indirect method).

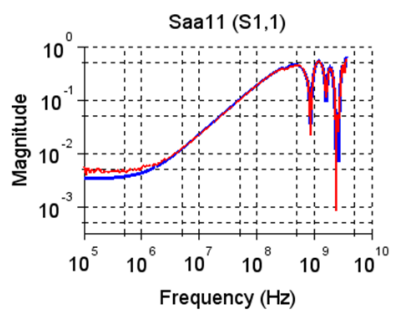

Direct Method

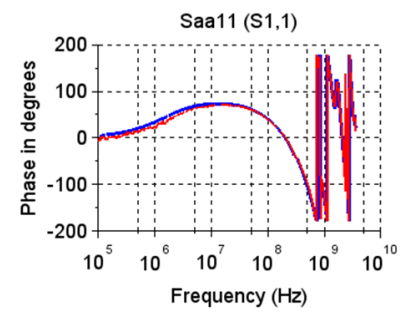

Indirect Method (Saa)

Fig. 7. Estimated S-parameters vs. fully measured S-parameters (1)
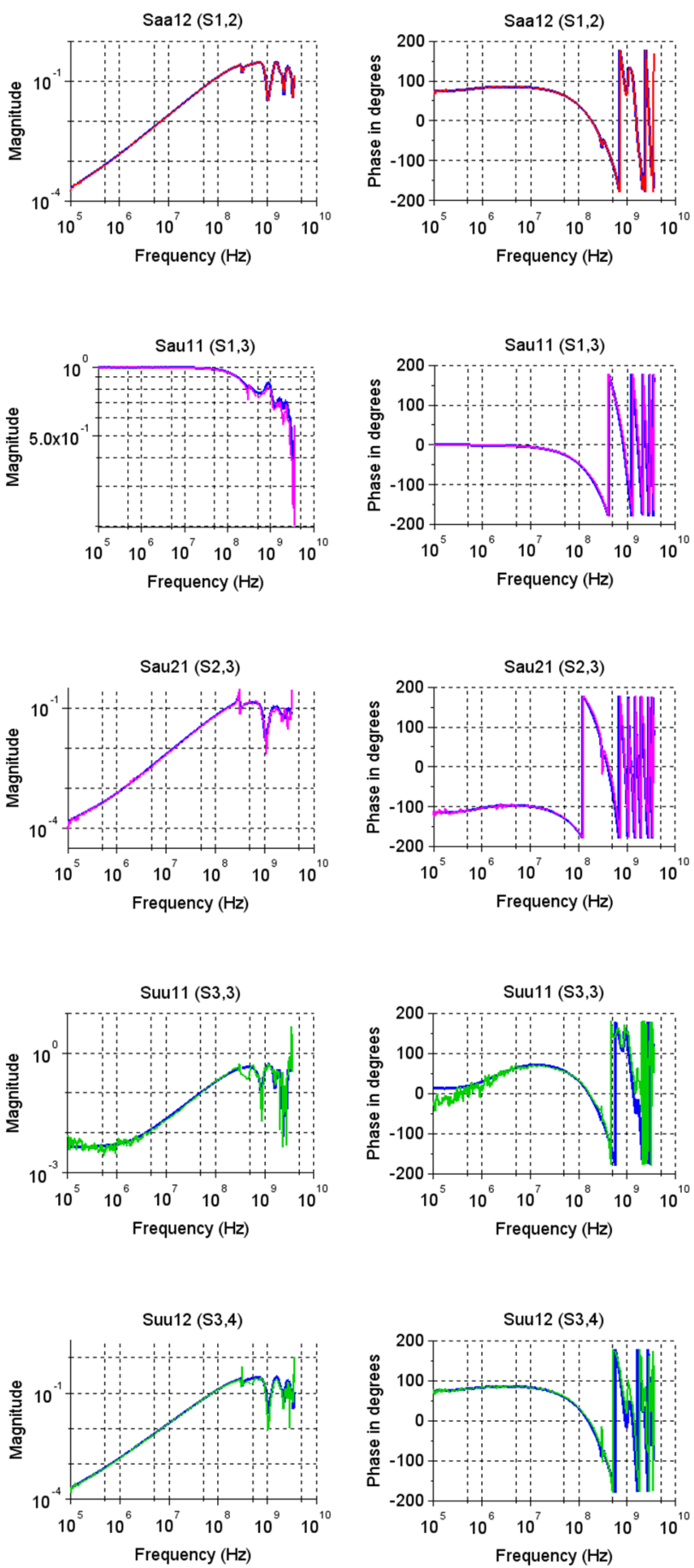

Direct Method

Indirect Method (Saa)

Indirect Method (Sau)

Indirect Method (Suu)

Fig. 8. Estimated S-parameters vs. fully measured S-parameters (2)

The calculation is carried out point by point over all the frequency range. The Saa parameters and the Sau parameters show a good agreement. The sign correction algorithm gives the exact phase values of the Sau parameters. The results of Suu parameters are less accurate because of the small variations of the first two matrices (Saa and Sau) used in their calculation. Also, because of the difference between the two loads using at the indirect ports but they are good enough over almost the entire frequency range of measurements. 
Next, a simultaneous injection of a $1 \mathrm{~V}$ common source noise is injected on the direct ports (1 and 2). The residual singleended voltage on each pins of the component is calculated, as presented in Fig. 9. Then, the differential voltage induced on the component is computed, as shown in Fig. 10.

The direct voltages are calculated, by (18) to (21), using the S-parameters of the DUT measured directly using the 4port direct measurement.
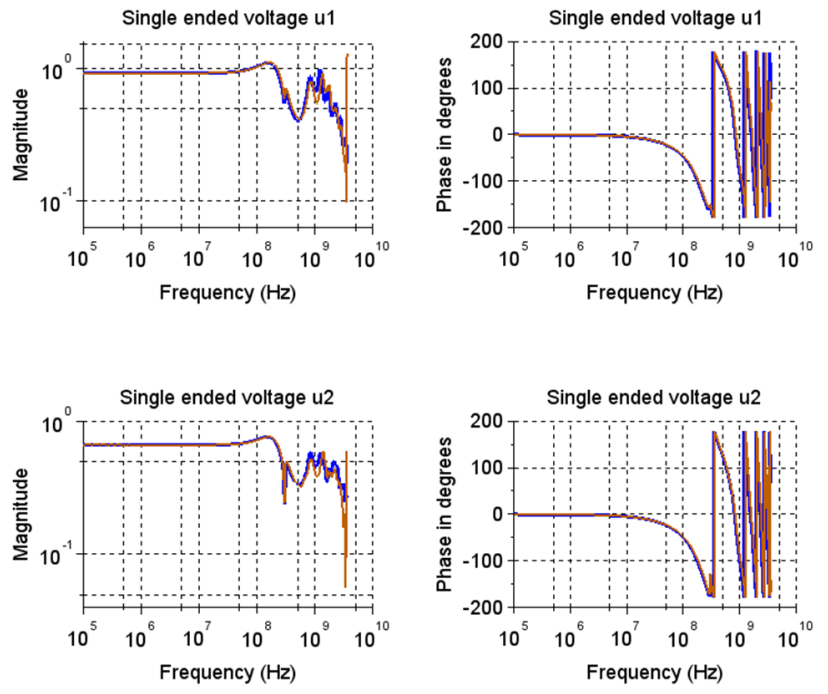

Direct Method

Indirect Method (voltages)

Fig. 9. Estimated single-ended voltages at the pins of the obsolete component
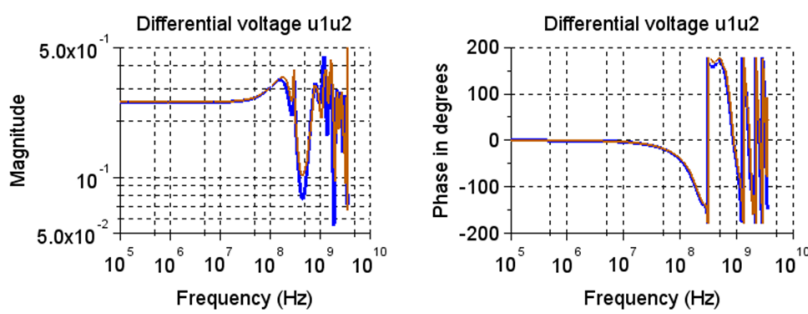

Direct Method

Indirect Method (Diff. voltage)

Fig. 10. Estimated differential voltage induced at the pins of the obsolete component

The estimated single-ended voltages present good agreement up to $3 \mathrm{GHz}$. The difference observed in high frequencies is due to the variations in the characteristics of the charges used on the indirect ports. In addition, the differential voltage is well estimated with good precision up to $3 \mathrm{GHz}$.

\section{CONCLUSION}

This paper proposes to use an indirect measurement method for S-parameters to deal with the obsolescence of components in complex electronic equipment. The method consists, first, in elaborating the equivalent "black box" model of the transfer function between the input connector of an equipment and an obsolete component mounted in one of its boards. Then, this multiport S-parameter model is used to estimate the residual voltages induced on pins of the component to replace.
We have developed a new sign correction algorithm which corrects the phase inversion of the all the parameters. Therefore, it allows giving the exact value of the magnitude and the phase of the estimated differential voltage.

An application of this method on a PCB board was presented, compared to the results of a full measurement using the VNA. The results are good from $100 \mathrm{kHz}$ to $3 \mathrm{GHz}$. Other studies are in progress in order to apply this approach on a real integrated circuits in complex equipment. Finally, this method could quickly bring satisfactory results when faced with the problem of the obsolescence of components in complex electronic equipment.

\section{ACKNOWLEDGMENT}

This study is supported by the IRT Saint-Exupery foundation (a French Institute of Technology) under the FELINE project. The authors would like to thank IRT, LAAS and all the project partners (Safran, Airbus, Continental, Liebherr, Actia, Thales, etc.) for funding and supporting this work. Also, special thanks to André Durier for providing the printed circuit board used in the experimental validation.

\section{REFERENCES}

[1] M. Amellal, "Modélisation l'immunité Électromagnétique des composants en vue de la gestion de l'obsolescence des systèmes et modules électroniques", Thesis - INSA Rennes, December 2015.

[2] R. Perdriau, "Taking into Account Obsolescence in the EMC Performance of Integrated Circuits and Systems", IEEE EMC HK Chapter Technical Seminar, May 2013.

[3] G. Duchamp, T. Dubois, A. Ayed, C. Marot, H. Frémont, "Measurement and simulation of electromagnetic drift for obsolescence management in electronics", $16^{\text {th }}$ International Conference on Thermal, Mechanical and Multi-Physics Simulation and Experiments in Microelectronics and Microsystems, 2015.

[4] A. Ayed, "Développement de méthodologies pour l'extraction et la construction des macromodèles d'immunité électromagnétique appliqués aux circuits intégrés", Thesis - Université de Bordeaux, December 2014

[5] A. Durier, C. Marot, O. Alilou, "Using the EM simulation tools to predict EMC immunity behavior of an automotive electronic board after a component change", International Symposia and Workshops on Electromagnetic Compatibility, Bruges 2013.

[6] N. Maeda, K. Ichikawa, T. Sekine, "Mathematics of 2r-Port SParameter Estimation by the r-port Measurements", IEEE Electrical Design of Advanced Packaging \& System Symposium, 2013.

[7] J. Ou and M. F. Caggiano, "Determine Two-Port S_Parameters from One-Port Measurements Using Calibration Substrate Standards", Electronics Components and Technology Conference, 2005.

[8] N. Maeda, T. Sekine, "An Indirect Measurement Method for Multiport S-Parameters with Reduced Number of Measurements", IEEE 2016.

[9] N. Maeda, S. Fukui, T. Sekine, Y. Takahashi, "An Indirect Measurement Method for S-Parameters which is based on Reduction to Eigenvalue Problem ", IEEE 2017.

[10] N. Maeda, T. Sekine, "Indirect Measurement Method for S-Parameters with a Recursive Procedure", IEEE 2019.

[11] T. Reveyrand, "Multiport conversions between S, Z, Y, h, ABCD and T parameters", IEEE 2018. 